\title{
A (IM)POSSIBILIDADE DA FIDELIDADE NA INTERPRETAÇÃO DA LÍNGUA BRASILEIRA DE SINAIS
}

\author{
Andréa da Silva Rosa
}

(...)a tradução é ainda uma arte puramente empírica, cujos_segredos cada tradutor tem de redescobrir por conta própria ( e à custas dos leitores).( RÓNAI, 1952, p.24)

\section{RESUMO}

Este artigo pretende apresentar a reflexão desenvolvida na minha dissertação de mestrado, quando me aproximei dos Estudos da Tradução e das questões de fidelidade envolvidas na atuação do intérprete de língua de sinais a partir da perspectiva da descontrução. O intérprete não se limita a transpor mecanicamente um discurso do português para a língua de sinais. E se traduzir é antes de tudo a sobrevida do texto da língua de partida na língua de chegada, interessa-nos refletir acerca das especificdades, dos riscos e dos resultados dessa sobrevida no ato interpetativo da língua de sinais, com vistas a embasar teoricamente a impossibilidade de fidelidade.

\section{PALAVRAS CHAVES}

Descontrução; Intérprete de língua de sinais; Fidelidade, Surdez, Sobrevida.

\section{THE (IM)POSSIBILITY OF FIDELITY IN SIGN LANGUAGE INTERPRETATION}

\section{ABSTRACT}

This article aims to present the reflections I developed in my Master's dissertation, where I approached translation studies and the fidelity issues involved in the work of a sign language interpreter, from the deconstruction perspective. The interpreter does not limit himself or herself to mechanically transferring a speech from Portuguese into sign language only. And since translation is above all the prolonged existence of the text out of the original language into the destination language, we are mostly interested in the reflections on the specificities, risks and results of this prolonged existence in the sign language interpretation act, expecting to explain theoretically how impossible fidelity is.

\section{KEY WORDS}

Deconstruction; Sign language interpreter; Fidelity; Deafness; Prolonged existence. 


\section{ARTIGO \\ Processos Tradutórios, Línguas de Sinais e Educação \\ Grupo de Estudos e Subjetividade}

\section{INTRODUÇÃO}

Rónai, em dois de seus livros sobre tradução, Escola de Tradutores (1952) e a Tradução Vivida (1976), faz reflexões sobre a sua prática e coloca a tradução de obras literárias é acima de tudo, uma arte. Enquanto tal, uma tarefa impossível. Para exemplificar a impossibilidade da tradução literária, ele compara a finalidade da tradução com a finalidade do artista ao retratar a sua obra.

O objetivo de toda arte não é algo impossível? O poeta exprime (ou quer exprimir) o inexprimível, o pintor reproduz o irreproduzível, o estatuário fixa o infixável. Não é surpreendente, pois, que o tradutor se empenhe em traduzir o intraduzível. (RÓNAI, 1952, p.3)

Essa impossibilidade também se relaciona, segundo Rónai (1952), com o fato de que, “ninguém pensa além do idioma” p.14; ou seja, há certos conceitos e significados que só podem fazer sentido por pessoas que falam determinada língua. Por exemplo: o famoso trocadilho italiano: traduttori/traditori torna-se de difícil compreensão em idiomas em que não seja possível fazer esse jogo com as palavras. Nesse instante, o tradutor já se torna traidor para significar no idioma estrangeiro o sentido do trocadilho italiano. "Não existe nenhuma língua capaz de dar conta de outra língua, pois a língua se apresenta como uma formação que se fecha sobre si mesma. Só dentro dela sendo possível, talvez, exprimir o que é seu modo de construção”.(SILVEIRA JR.,198, p. 16).

O trocadilho italiano exprime com muita propriedade a representação generalizado que se tem contra a tradução. Constantemente em textos que tratam do assunto as traduções são tidas como secundárias, precárias e um “mal necessário”.

Segundo Rónai (1952), as palavras intraduzíveis de um idioma para outro podem parecer, num primeiro momento, a um tradutor desatento, o maior problema. Entretanto, não é o que ocorre, pois, para palavras que não têm equivalência textual na língua-alvo, é possível fazer uso de notas de rodapé; além disso, o tradutor não se ilude em realizar uma tradução desejando alcançar a fidelidade. Está claro que não é possível (con)formar a obra do original na língua de chegada, na tentativa de obter a “fidelidade”.

Para Rónai (1952), a dificuldade da tradução reside justamente nas palavras traduzíveis: são essas que enganam ou alimentam a ilusão de ser possível a “fidelidade” da tradução. 
Essa armadilha se faz presente também na tradução do português para a língua de sinais. O intérprete, ansioso por ser "fiel” e exato, faz traduções que mudam completamente o sentido do português, como ocorreu na seguinte situação: o intérprete, julgando estar sendo “fiel” à palestrante ouvinte, traduziu a seguinte frase: A pobreza é muito séria (em português), da seguinte forma: pobre sério (em língua de sinais).

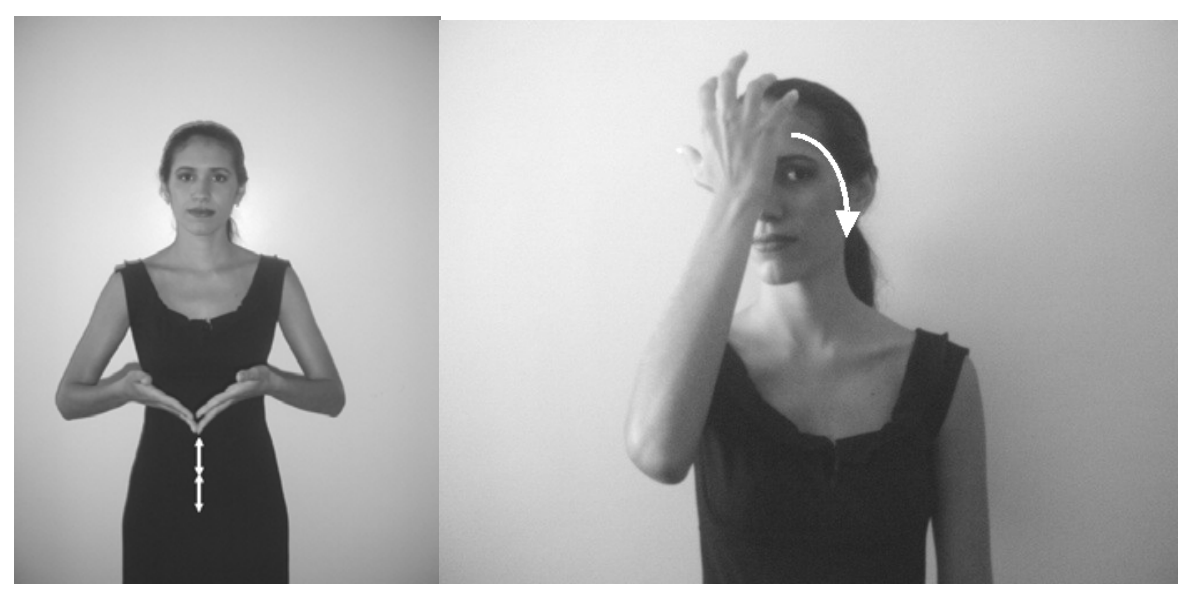

Pensa-se, geralmente, que a tradução fiel é a literal. No exemplo citado, as palavras e os sinais foram os mesmos, porém o sentido foi transformado e a tradução para a língua de sinais ficou fora do contexto da palestra.

Falava-se sobre a educação dos surdos no Brasil, e a palestrante explicava que o problema maior não estava na surdez e, sim, em ser pobre, pois surdos que tiveram acesso a melhores recursos apresentavam desempenho escolar semelhante ao ouvinte.

A tradução poderia ter sido: Pobre problema difícil.
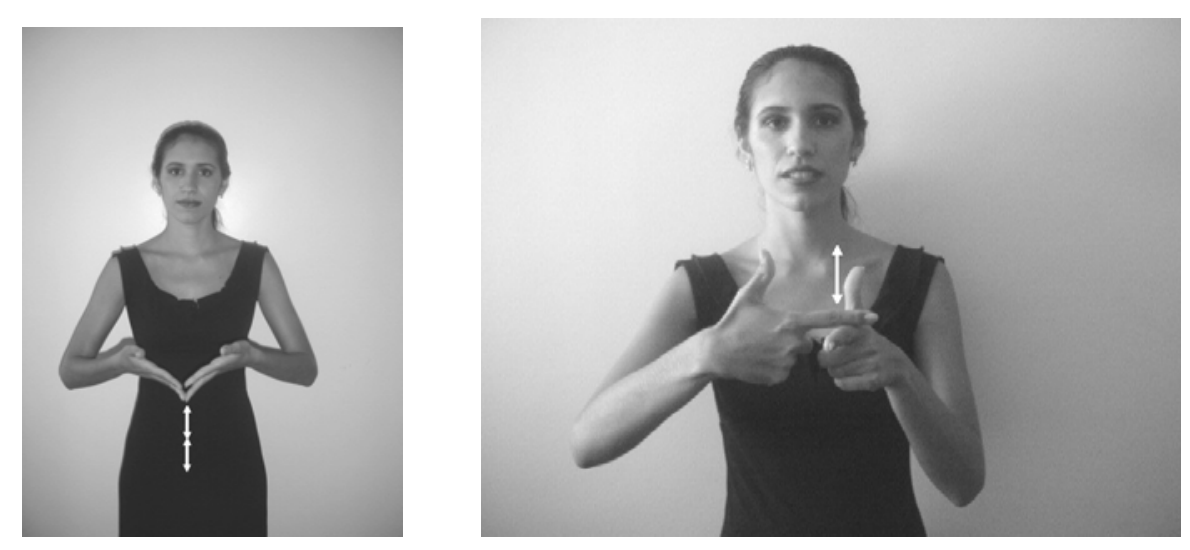


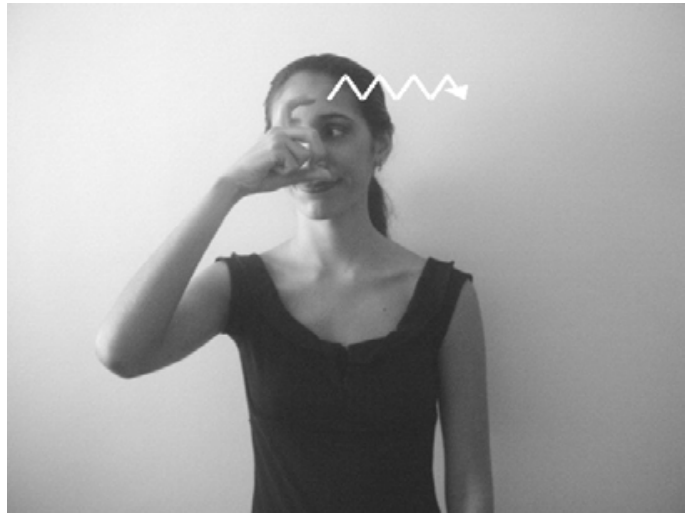

Segundo Rónai (1952), a fidelidade do tradutor não se relaciona somente à língua de partida, mas com as duas línguas, ou seja, a língua de partida e a língua de chegada. O compromisso de fidelidade requereria do tradutor a busca de um equilíbrio entre a alteridade e a identidade com o original. Esse compromisso não se restringiria somente na relação texto original/tradutor, mas existiria a preocupação de ser fiel às expectativas e às necessidades do leitor pretendido.

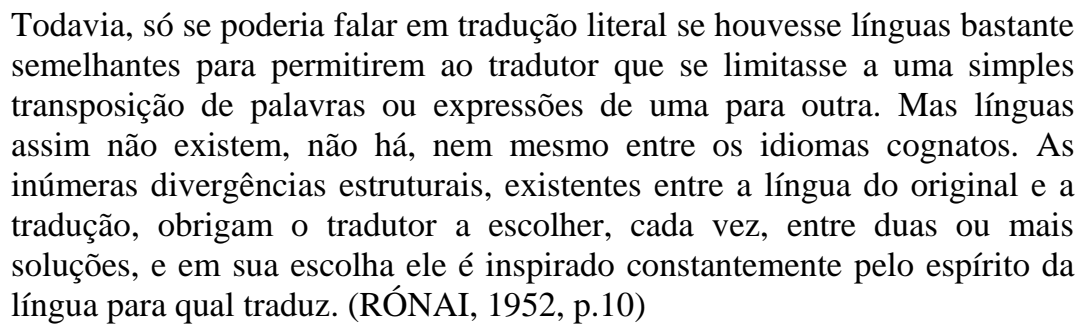

As dificuldades do tradutor/intérprete são constantes e não há problema de tradução definitivamente resolvido, pois as palavras se apresentam em contextos diferentes que lhes alteram o sentido, alterações que por serem muito sutis são às vezes quase imperceptíveis. “Assim, nosso ofício de tradutores é um comércio íntimo e constante com a vida”, como diz Valery Larbaud; não é, de forma alguma, um jogo de paciência com palavras mortas e fichadas para sempre.” (RÓNAI, 1952, p.8). As palavras não possuem sentido isoladamente, mas o sentido lhes é atribuído pelo contexto.

O tradutor precisa conhecer as minúcias semelhantes da língua de partida com a língua de chegada para poder perceber além do conteúdo estritamente lógico: “traduzir é a maneira mais atenta de ler” (RÓNAI, 1952, p.31). O tradutor não deve traduzir palavra a palavra; nem pode utilizar o texto de partida como um tema sobre o qual improvisa livremente. $\mathrm{O}$ ato tradutório só acontece a partir de uma mensagem que compreendida pelo leitor/tradutor a 


\section{ARTIGO \\ Processos Tradutórios, Línguas de Sinais e Educação \\ Grupo de Estudos e Subjetividade}

transforma em nova mensagem compreensível ao leitor da língua de chegada. Segundo Paulo Ottoni (1996), tradução é a materialidade de uma leitura.

A leitura é acontecimento que revela a intervenção e a integração do leitor com a língua. "A tradução e a leitura são fenômenos complexos de construção e transformação de significados - de sentidos - que ocorrem através da fusão do tradutor ou leitor com o texto.” (OTTONI, 1996, p. 19).

Na abordagem estrutural e formal, a compreensão, sem a participação do sujeito leitor, dá-se a partir da leitura concebida como um processo que retira significados previamente colocados no texto. Nesta abordagem, o sujeito aparece somente no momento da interpretação do texto, após sua compreensão. A separação entre compreensão e interpretação, em dois distintos momentos, é condição necessária para o estabelecimento e o fortalecimento dessa abordagem que concebe essa separação como constitutiva do processo de leitura e de tradução, separando, dessa forma, o sujeito do objeto. (OTTONI, 1996)

Os pressupostos teóricos que sustentam a abordagem estrutural e formal, que distingue a compreensão da interpretação e o sujeito do objeto, são os mesmos que sustentam a idéia de que há uma intenção inicial no texto. Se há uma intenção, que foi colocada no texto, é porque existe um sentido único que pode ser decodificado através de uma informação. Ou seja, em um texto, há intenção de um indivíduo ou de um grupo, independente de quem o produziu, mas acredita-se que essa intenção foi sedimentada no texto e ali permanece, para ser recuperada pelo leitor/tradutor e, depois, transportada para outra língua, quando esse mesmo significado será recuperado pelo leitor pretendido, na língua traduzida.

Segundo Ottoni (1996), na abordagem pós-estruturalista da linguagem, é possível afirmar que “compreender é interpretar”, isto é, não há compreensão de um texto, sem a intervenção de um sujeito. Contrária à postura anterior, que pressupõe uma relação simétrica entre leitor e texto, a dessimetria leitor/tradutor e texto mostra que uma significação não é única.

A leitura é dirigida por diversos fatores, tais como experiência e conhecimento de cada leitor e condições de produção de cada texto, tanto na língua de partida, quanto na língua de chegada. Entretanto, isso não isenta o tradutor da busca pelo sentido, ou seja, da compreensão da obra original; sem isso, não haveria razão para traduzir. Porém, o tradutor não pode restringir-se a buscar um único sentido, como se estivesse pré-determinado: é necessário considerar que toda obra é algo aberto, que pode ser cortada e recortada por múltiplas leituras 


\section{ARTIGO \\ Processos Tradutórios, Línguas de Sinais e Educação \\ Grupo de Estudos e Subjetividade}

e interpretações e que a tradução não deve fechar essas leituras, limitando-se a apenas uma, quando existe a possibilidade de se obter mais de um sentido.

Assim sendo, o sentido será construído pelo leitor e essa construção estará dependente de todo o contexto sócio-histórico e psicológico, assim como esteve, com o autor, no processo de produção da obra original e, com o leitor/tradutor, no momento da produção do outro/mesmo texto na língua de chegada.

O sentido não preexiste à compreensão, entretanto é constituído por ela; todavia, o tradutor mais constrói, reconstrói, transforma e recria do que simplesmente transporta algo que estava a princípio imutável no texto dito como original. A tradução nos obriga a investigar detalhadamente a função de cada palavra, esquadrinhar atentamente o sentido de cada frase e, finalmente, reconstruir a paisagem mental do autor e descobrir-lhe o que o autor quis dizer [...] “a tradução é um mundo de minúcias.” (RÓNAI, 1952, p.43). Em seu livro a Tradução Vivida (RÓNAI, 1976:1) o autor define tradução como [...] “a reformulação de uma mensagem num idioma diferente daquele em que foi concebida”.

Para que isso ocorra, é necessário que a mensagem da língua de chegada seja submetida às mesmas vicissitudes da mensagem pretendida no original, passando por nova expressão lingüística. E no caso das línguas de sinais, não só a mensagem do original será transformada, mas também a modalidade da língua de partida passando de uma língua oralauditiva ou escrita para uma língua visual espacial.

Segundo Rónai (1952), as duas fidelidades, para com a língua de partida e com a língua de chegada, instituem a diferença que se faz a própria razão da tradução. Se não fossem diversos sistemas, as culturas, os momentos históricos não haveria motivo para traduzir. Mas, se não houvesse a tentativa da "fidelidade”, ainda que em vão, com que o autor do original “quis dizer” e de encontrar meios de expressão para essa suposta intenção comunicativa, também não haveria tradução, diálogo, intertextualidade, intersubjetividade, mas tão somente diversos discursos cruzados, desconexos e mutuamente incompatíveis.

Sendo assim, a tradução fiel é alcançada muito menos pela tradução literal, do que por uma substituição contínua. “A arte do tradutor consiste justamente em saber quando pode verter e quando deve procurar equivalências.” (RÓNAI, 1952, p.13)

Dito de outra forma, quando se deixa de pensar na tradução como uma atividade puramente mecânica, em que um indivíduo conhecedor de duas línguas vai substituindo, uma por uma, as palavras de uma frase na língua A por seus equivalentes na língua B, o papel do 


\section{ARTIGO \\ Processos Tradutórios, Línguas de Sinais e Educação \\ Grupo de Estudos e Subjetividade}

tradutor torna-se singularmente mais importante e se transforma numa atividade seletiva e reflexiva.

Procurar equivalência, para um tradutor, não é tarefa das mais simples, pois na língua de chegada nem sempre há equivalências absolutas: uma frase ou expressão da língua de partida normalmente pode ser traduzida de maneiras diversas, sem que haja uma forma melhor do que a outra. "Haverá muitas traduções boas, mas não a tradução boa de um origina”l. (RÓNAI, 1952, p.13). Isso porque cada um vive a língua materna de forma única. Várias pessoas podem aprender uma língua estrangeira de uma única forma (na mesma escola, com os mesmos livros didáticos, submetidos à mesma pedagogia); entretanto, o mesmo não acontecerá com a língua materna. Podemos falar várias línguas, mas é sempre numa delas que habitamos. Para assimilar totalmente duas línguas seria necessário viver em dois mundos diferentes ao mesmo tempo.

Normalmente, o tradutor realiza seu trabalho a partir de uma língua estrangeira para a sua língua materna. Ocorre, no caso do ILS o inverso: em geral, é um ouvinte que verte sua língua materna (português) para uma outra que lhe é estrangeira (língua de sinais), isto é, o estrangeiro (intérprete) verte para uma comunidade interpretativa uma língua que lhe é estrangeira. Usualmente, o ILS aprende a língua de sinais em comunidades formadas por surdos majoritariamente, a que chamarei, genericamente, de Comunidades Surdas.

Como existem, no Brasil, várias comunidades surdas, que vivenciam a língua de sinais de uma forma própria (dialetos), cada intérprete terá um aprendizado único com a língua de sinais, ou seja, não há uma língua de sinais estabelecida como “culta”, ou seja, não há escolarização da língua de sinais, o que acontece é que o ensino da língua de sinais se dá em situação não formal. A aprendizagem da língua de sinais pelo intérprete é não escolar, isso é diferente do que ocorre com as outras línguas, pois só se aprende na lida com os próprios usuários.

Dessa forma, o intérprete irá carregar as marcas das variações dialetais do contexto em que aprendeu os sinais.

Na interpretação de línguas orais, o intérprete pode se tranqüilizar (mais ou menos), pelo fato de verter uma língua estrangeira para uma língua materna que é a dele, por ter uma certa garantia de ter tido uma aprendizagem formal e ter formalizado essa aprendizagem através de testes de proficiência oferecidos por diferentes órgãos competentes e reconhecidos.

Salvo os filhos ouvintes de pais surdos que são maternados na língua de seus pais, ou seja, a língua de sinais. (C) ETD - Educação Temática Digital, Campinas, v.7, n.2, p.123-135, jun. 2006 - ISSN: 1676-2592. 


\section{ARTIGO \\ Processos Tradutórios, Línguas de Sinais e Educação \\ Grupo de Estudos e Subjetividade}

Ele pode se sentir confortável em fazer uma tradução ainda que para diferentes regiões do Brasil.

O mesmo não acontece com o intérprete de língua de sinais. Ele não pode ter a ilusão de estar preparado ou ter a segurança de um intérprete do Estado de São Paulo em realizar uma tradução compreensível ou satisfatória para um grupo de surdos que pertença a outros Estados Brasileiros.

As dificuldades da atividade tradutória reside justamente nos diferentes modos de olhar a realidade e as formas distintas de nomeá-la. Os Estudos da Tradução nos remete a uma situação contraditória: quanto mais se sabe sobre o modo como as pessoas se comunicam, mais se conhece os obstáculos à tradução. Por outro lado, suponho que quanto mais o tradutor está ciente disto, melhor aprende a contorná-los de modo a tentar preservar, na tradução, senão toda, pelo menos, o máximo de "fidelidade" ao original.

2. Limites e Abusos no Ato Interpretativo

Como vimos no item anterior, o ato interpretativo será efeito do conhecimento que o ILS tem sobre comunidade surda, língua de sinais e assunto versado.

O trabalho do intérprete de língua de sinais consiste em pronunciar, na língua de sinais, um discurso equivalente ao discurso pronunciado no português oral ( ou vice-versa).

Segundo Humberto Eco (1997), há uma grande diferença entre usar um texto e interpretá-lo. O uso estende, sem nenhum parâmetro, o universo de sentido do texto. A interpretação, ao contrário, respeita a coerência do texto, ou seja, a unidade, a continuidade de sentido que ela possui e o contexto em que está inserido. "Se há algo para ser interpretado, a interpretação deve falar de algo que deve ser encontrado em algum lugar, e de certa forma respeitado”. (ECO, 1987, p. 50).

Quando há, por parte do intérprete, uso da mensagem original para o próprio proveito, essa situação deixa o surdo numa condição de grande dependência do ILS; este profissional, se é que podemos classificá-lo assim, torna-se o tutor desse surdo.

O abuso na interpretação é um fator complicador para a comunidade surda, justamente pela sua especificidade e sua história de exclusão social.

O fator complicador está ligado ao fato de ser uma profissão não regulamentada e por não haver qualquer instituição de ensino que se destine a formar intérpretes, estes são, geralmente pessoas do convívio e da confiança da comunidade surda. Quando o intérprete não pertence uma comunidade surda, seu trabalho enfrenta dificuldades e, geralmente, está fadado ao fracasso, porque sua fala não terá crédito, “o intérprete é a pessoa em que o surdo mantém 


\section{ARTIGO \\ Processos Tradutórios, Línguas de Sinais e Educação Grupo de Estudos e Subjetividade}

extrema confiança. Tanto profissional como pessoal” (FENEIS ). Sendo esse intérprete escolhido pela comunidade surda, dificilmente a sua “fala” ou interpretação será questionada , até que ele seja pego em contradição. Caso isso ocorra, já terá feito muito uso de diversos discursos, criando um ciclo vicioso, que poderia ser assim explicado: "quanto mais amigo eu for do surdo, mais ele acredita em mim, mais eu uso da mensagem para manipular e mais ele acredita em mim e assim sucessivamente.

Essa é uma das grandes razões de muitos surdos terem desconfianças enormes com relação à atuação dos intérpretes e, em conseqüência disso, alguns surdos impõem ao intérprete exigências incabíveis , chegando ao extremo de se envolverem na vida pessoal dos ILS.

Caso o surdo queira se aproximar do professor e lhe direcionar uma pergunta, quase sempre o fará com auxilio do intérprete que, por sua vez, estará entre a pergunta ao professor e a resposta para o aluno.

O português escrito, principalmente os termos idiomáticos e as gírias, como sabemos, é para a maioria da comunidade surda, de difícil compreensão. Por essa razão, caso esse surdo procure compreender a fala do professor pela interação no texto escrito, normalmente, em algum dado momento, pedirá para o intérprete uma explicação ou outra de alguns conceitos da língua portuguesa.

Logo, dificilmente o surdo tem acesso com clareza ao original, quer seja esse original a fala do professor, quer seja um texto escrito. Mesmo que o surdo perceba atitude do intérprete, e quase sempre ele percebe, é quase que improvável que ele tenha como denunciar e - ainda mais grave - não há para quem ou onde denunciar.

A palavra é evanescente, a interpretação escapa a provas. A menos que esteja sendo filmado diariamente, o intérprete de língua de sinais tem total "liberdade” para atuar, ou seja, é de sua escolha e decisão interpretar a aula ou fazer uso dela para proveito seu.

Federação Nacional para a Educação e Integração do Surdo - FENEIS . HYPERLINK "http://www.feneis.com.br" www.feneis.com.br .

Boa parte das considerações que farei às páginas seguintes são baseadas nas experiências que acumulei ao longo dos anos: interpretando, ouvindo intérpretes, observando as relações que se estabelecem entre os distintos pareamentos, fazendo parte da lista de discussão compostas por ILS e etc..

Refiro-me a tais exigências: a) disponibilidade 24 horas; b) priorizar as necessidades dos surdos acima de suas próprias prioridades;c) não avisar o intérprete com antecedência, enviando e-mail ou mensagens de texto e querer ser atendido naquele momento; d) interferir nas amizades; e) querer saber quais os locais que freqüenta.

(C) ETD - Educação Temática Digital, Campinas, v.7, n.2, p.123-135, jun. 2006 - ISSN: 1676-2592. 
E, caso o surdo resolva não mais utilizar os serviços desse intérprete na sala de aula, é bem possível que ele fique sem nenhum auxílio: em conseqüência da não-oficialização da profissão e dos baixos salários, é raro conseguir um intérprete na sala de aula, independentemente da qualidade de sua atuação.

E quais seriam os limites da interpretação, uma vez que, como já vimos, o sentido é construído pelo receptor da mensagem não há somente um único sentido a ser decodificado e extraído. Isso não torna o processo de interpretação incontrolável, há, na mensagem, pistas, o contexto, que nos remetem a vários sentidos que serão confirmados por outros elementos do texto. Ou seja, no entendimento global da mensagem, não pode o texto/discurso ser interpretado fora do seu contexto. Em outras palavras, a interpretação/ compreensão de uma parte do texto será válida se estiver de acordo todo o texto/mensagem.

Conforme assinalamos anteriormente, ao nos referirmos ao entendimento de Eco, a interpretação de um texto, no caso do intérprete de língua de sinais, configura-se na compreensão da mensagem e ocorre sempre que respeitamos a sua coerência. Segundo Eco (1993, p.76):

\footnotetext{
(...) qualquer interpretação feita de uma certa parte de um texto poderá ser aceita se for confirmada por outra parte do mesmo texto, e deverá ser rejeitada se a contradisser. Neste sentido, a coerência interna do texto domina os impulsos do leitor, de outro modo incontroláveis.
}

Se o uso de um texto/mensagem é ilimitado, a sua interpretação não o é. O limite da interpretação/compreensão é dado, em primeiro lugar, pela idéia segundo a qual um texto ou discurso é um todo coerente. Ou seja, ao compreender a mensagem, mais especificamente a matéria exposta pelo professor na sala de aula, o ILS deve considerar todo o contexto da matéria, e não somente uma fala específica. Nesse caso, havendo dúvidas, é possível ter acesso ao professor e perguntar-lhe o que quis dizer em determinadas situações.

É preciso salientar que o intérprete na sala de aula parte sempre de uma realização verbal precisa, de uma unidade lingüística concreta, perceptível pela audição, e, por princípio, ele não pode modificar a construção verbal original, a montagem do texto anteriormente feita, pois é essa composição, esse arranjo que vai oferecer-lhe as marcas, as pistas para sua construção de uma outra/mesma “aula”, em língua de sinais.

Entretanto, o compromisso do intérprete não se define tão somente na relação no português/língua de sinais. Como instrumento humano, suporte para a educação dos surdos nas salas de aulas inclusivas, é de se esperar que o intérprete tenha, como de fato a maioria o 
tem, em grau passível de certa variação, é verdade, um compromisso com as expectativas do aluno surdo. 


\section{REFERÊNCIA:}

AUBERT, F. H. As (In)fidelidades da tradução: servidões e autonomia do tradutor. 2. ed. Campinas: UNICAMP, 1994.

.Introdução. In: Conversas com tradutores balanços e perspectivas da tradução. BENEDETTI, I. C. e SOBRAL, A (Org.). São Paulo: Parábola Editorial, 2003.

BENEDETTI, I. C. e SOBRAL, A (orgs.) Conversas com tradutores balanços e perspectivas da tradução. São Paulo: Parábola Editorial, 2003.

DELISLE, J. e WOODSWORTH, J. Os tradutores na história. São Paulo: Ática, 2003.

DERRIDA, J. Torres de Babel. Tradução de Junia Barreto. Belo Horizonte: FMG, 2002.

ECO, H. Interpretação e superinterpretação. São Paulo: Martins Fontes, 1993.

FENEIS. O que é interprete de língua de sinais para as pessoas surdas? Belo Horizonte/MG, 1995.

FENEIS.Intérprete.Disponível: http://www.feneis.com.br/interpretes/postura.shtml. Acesso em: 23 de agosto de 2004

OTONNI, P. A leitura como tradução. In: ARROJO, R. O signo descontruído: implicações para a tradução, a leitura e o ensino. Campinas, SP: Editora Pontes, 1992.

RÓNAI, P. Escola de tradutores. Os Cadernos de Cultura: Ministério da Educação e Saúde.

.A Tradução Vivida. Rio de Janeiro: Educom, 1976.

ROSA, A da S. A presença do intérprete de língua de sinais na mediação social entre surdos e ouvintes. In: SILVA, I. R.; KAUCHAKJE, S.; GESUELI, Z. M. (Org.). Cidadania, Surdez e Linguagem. São Paulo: Plexus, 2003.

ROSA, A da S. Entre a visibilidade da tradução da língua de sinais e a invisibilidade da tarefa do intérprete. 2005. 199p. Dissertação ( Mestrado em Educação) - Faculdade de Educação, Universidade Estadual de Campinas. Campinas, 2005.

SILVEIRA Jr. P. M. Da. A tradução: dados para uma abordagem psicanalítica. Rio de Janeiro: OUTRA, 1963.

THEODOR, E. Tradução: ofício e arte. 3. Ed. São Paulo: Cultrix. 
